$1-1-1962$

\title{
Labor utilization in slaughtering operations in northeastern United States
}

\author{
Kenneth D. McIntosh \\ Clarence Earl Trotter
}

Follow this and additional works at: https://researchrepository.wvu.edu/ wv_agricultural_and_forestry_experiment_station_bulletins

\section{Digital Commons Citation}

McIntosh, Kenneth D. and Trotter, Clarence Earl, "Labor utilization in slaughtering operations in northeastern United States" (1962). West Virginia Agricultural and Forestry Experiment Station Bulletins. 480.

https://researchrepository.wvu.edu/wv_agricultural_and_forestry_experiment_station_bulletins/452 @ WVU. It has been accepted for inclusion in West Virginia Agricultural and Forestry Experiment Station Bulletins by an authorized administrator of The Research Repository @ WVU. For more information, please contact ian.harmon@mail.wvu.edu. 

Digitized by the Internet Archive in 2010 with funding from

Lyrasis Members and Sloan Foundation 


\section{Bulletin 480, June 1962}

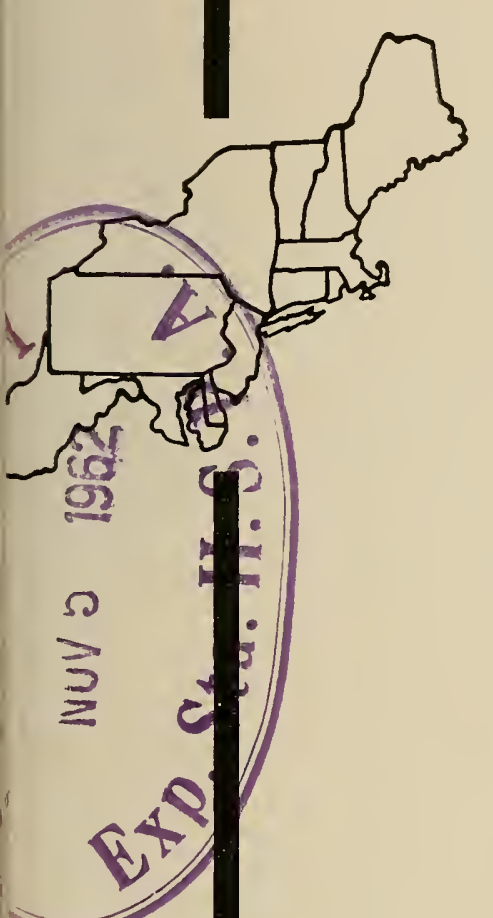

\section{Labor Utilization}

in Slaughtering Operations of Plants

in Northeastern United States 


\section{ACKNOWLEDGMENT}

The authors express their appreciation for the support given this study by all members of the Northeast Livestock Technical Committee (NEM-7). An especial thanks is due to Enoch Tompkins, University of Vermont, and Dean Tuthill, University of Maine, for their assistance in collecting the data for this study, and to C. G. Randell, Farmer Cooperative Service, for his helpful suggestions. Finally, we appreciate very much the generosity of those slaughter plant owners and managers who allowed us to conduct the study in their plants.

\section{THE AUTHORS}

Kenneth D. McIntosh is Assistant Agricultural Economist in the West Virginia University Agricultural Experiment Station. Clarence E. Trotter is Associate Professor of Marketing, College of Agriculture. Pennsylvania State University.

West Virginia University Agricultural Experiment Station

College of Agriculture, Forestry, and Hone Economics A. H. VanLandingham, Director MORGantown 


\section{FOREWORD}

THE information contained in this report comes from a cooperative study conducted by certain Experiment Stations in Northeastern

United States and service agencies of USDA, with the courteous assistance of selected livestock slaughtering establishments in the Northeast. As part of their contribution to the Northeast Regional Livestock Marketing Project (NEM-7) "Factors Affecting the Efficiency of Livestock Marketing in the Northeast," the Experiment Stations in four states developed a sub-project entitles "An Eco110mic Analysis of the Physical and Monetary Costs Incurred in the Procuring, Slaughtering, and Distributing of Livestock, Meat, and Meat Products by Local and Wholesale Slaughtering Establishments." ${ }^{\prime}$ Under this sub-project a study of labor utilization in killing. room operations was initiated in late 1959. A group of medium and large slaughtering plants was selected and data were collected during 1959,1960 , and 1961.

The cooperating agencies are:

\section{State Agricultural Experiment Stations Maine Vermont Pennsylvania West Virginia}

\section{United States Department of Agriculture}

\section{Economic Research Service}

(Formerly Agricultural

Marketing Service)
Farmer Cooperative Service State Experiment Stations Div. Regional Coordinator

${ }^{1}$ At the beginning of the study, USDA defined wholesale plants as those not under federal inspection and whose annual slaughter exceeded $2,000,000$ pounds liveweight. Local plants were defined as those nonfederally inspected plants whose annual slaughter was more than 300,000 pounds liveweight, but less than 2,000,000 pounds. In 1960, however, USDA changed the titles of these plants. Wholesale plants became "large" and local plants became "medium" non-federally inspected plants. See: "Number of Livestock Slaughter Establishments March 1, 1955," USDA, AMS, June 15, 1955, and "Number of Livestock Establishments March 1, 1960," USDA, AMS, August 1960. 


\section{SUMMARY}

MONG the medium and large non-federally inspected slaughter plants in Northeastern United States, many alternative production methods are used in the kiiling and dressing of hogs and cattle. These various arrangenents are especially noticeable among plants killing hogs. In addition to production differences due to varying quantities of capital and labor, there are differences due to the many ways these factors are arranged and used within individual plants.

The information obtained in this study indicates an inverse relationship between the annual volume of hogs slaughtered and the labor input per head. The on-line labor used per head decreased by almost three-fourths as the annual volume increased from less than 1,000 to approximately 100,000 head.

In striking contrast to the hog killing operations, the data obtained on cattle killing operations indicate very little or no relationship between annual volume of slaughter and the amount of labor used per head. At those plants slaughtering fewer than 1,000 head of cattle, the labor used per head appears to be higher than that used in the iarger volume plants. However, among plants slaughtering between 1,000 and 13,000 head annually, no consistent relationship is noted between the labor input per head and the annual volume.

A pragmatic set of labor standards for different stages in the killing and dressing of hogs and cattle, based on low labor-using plants under each stage, indicates that most plants could lower their labor input per head of hogs or cattle. 


\section{Labor Utilization in Slaughtering Operations of Plants in Northeastern United States}

\section{Introduction}

KENNETH D. MCINTOSH and CLARENCE E. TROTTER

CCORDING to data published by the USDA, there were 685 slaughter plants in the Northeast region in 1960." Ninety-seven Hof these were classified as federally inspected plants, 171 as large non-federally inspected plants, and 417 as medium non-federally inspected plants.

In spite of their functional similarity, these plants differed in many respects. As indicated by their titles some had federal inspection and some did not. The size of establishments ranged from a low annual kill of 500 head to a slaughter of 500,000 animals annually. The labor force varied from one man to abattoirs where several thousand people were employed. Some plants specialized in the slaughter of one species and class, such as hogs or bob calves, whereas at others all species and classes of livestock were killed. Throughout the region, there were plants that specialized in the production of sausage only. At the same time, there were establishments which handled fresh meat only.

There was considerable variation in the extent of the market area served by the three plant classifications. Federally inspected plants generally had the most extensive market areas. These larger marketing spheres arose not only from their normally larger operations, but also from the fact that they could move meat products across state boundaries. Large non-federally inspected plants generally served a smaller market than the federally inspected plants, but due to the lack of federal inspection their distribution area was limited to the boundaries of the state in which they were located. Medium non-federally inspected plants generally distributed meat and meat products in localized markets near their plant sites."

This study included information obtained from a representative group of large- and medium-sized plants. Federally inspected plants

2"Number of Livestock Slaughter Plants, Niarch 1, 1960," USDA, AMS, August 1960, p. 5. ${ }^{3}$ For a fuller description of slaughter establishments in the Northeast region, consult W. Va. Exp. Sta. Bul. 428, Characteristics of Livestock Slaughter Plants in Northeastern United States, June 1959. 
were excluded from the study. Altogether, 22 large- and 16 mediumsized plants were included in this report. Among these 38 plants, 27 had cattle slatuhtering operations that were studied, 22 had hog killing operations, and 8 had calf slaughtering operations.

\section{Hog Slaughtering Operations}

Hog hilling operations were studied in 22 plants, $t$ of which slaughtered only hogs, while 18 slaughtered both cattle and hogs. Nine of these plants were located in Maine, 7 in Pennsylvania, 5 in West Virginia, and 1 in Vermont. All of the plants in Pennsylvania and West Virginia had the necessary rolume to be classified as wholesale or large non-federally inspected plants. The plant in Vermont, and 7 of the 9 in Maine were classified as local or medium nonfederally inspected plants.

\section{ORGANIZATION AND PROCEDURE}

Typically, the slanghtering areas in these plants were so divided that there were separate lines for the hogs and cattle. Generally speaking. the order of flow through the slaughtering area followed a sequential pattern from the live animal to the dressed carcass. In order of their occurrence hogs were assembled, driven to shackling pens. shackled and hoisted, stuck, bled, scalded, dehaired, scraped, criscerated. split, trimmed, washed, inspected, branded, weighed, and mored into coolers. Washing and inspecting did not always occur in a regular pattern. At some plants, the carcasses were washed before and after erisceration. In other plants. washing occurred after the carcass was weighed. Thus, the placing of washing and inspecting in the above order was an arbitrary one. Such operations as stripping the casings, washing the stomach, separating the offal, and trimming the head were considered to be adjunct activities and seldom interfered with the morement of carcasses along the dressing line. In those plants that recorered a large portion of the edible offal, these adjunct actirities normally occurred in rooms next to the killing floor or directly underneath it.

Carcasses were mored along the rail by human or mechanical power. In the smaller plants. carcasses were pushed along the rail by laborers. In the larger plants. mechanical power. in the form of moring chains, was substituted in this operation. No matter which source of power was used, each worker was assigned a specific task to perform on the carcass as it passed along the line in front of his station. Generally speaking: the larger the number of workers, the greater was the degree of specialization. 
Functionally, these plants had a common purpose-meat production; however, a plant could choose among many means to achieve this objective. For example, hogs could be killed by using firearms, knives, hammers, electricity, and gas. The hair on a hog carcass could be removed manually with knives or it could be removed mechanically with the assistance of dehairers and depilators (wax dip), and singers. In some plants, large sums of money were invested in the most recently designed slaughtering equipment, whereas in other plants, there was practically no equipment on the killing floor. In the latter instance, the labor input per hog was higher than that of the highly mechanized plants.

The job specifications for each worker were subject to considerable modification among plants. At one plant a worker may be charged with the specific job of splitting each hog carcass as it moved along the line, whereas at another plant the worker who split the carcass may also be assigned the task of removing kidneys and facing hams. Under these circumstances, it was difficult to isolate and make timed observations of each job element along the killing line.

Considering the variations among plants, as discussed in the preceding paragraphs, some adjustments in the data were required in order that comparisons among plants conld be made. Since eacli job element could not be analyzed separately, several of them were combined under each of five stages. At any given plant, workers may or may not perform all of the jobs listed under each stage.

The amount of labor used in performing each job element was averaged for 10 timed observations. Starting time for a given task began when the worker reached for the animal or a piece of equipment to be used in performing the specific job. Stopping time was at that instant when the laborer released the carcass or piece of equipment that was used. An attempt was made to determine lag time, but this part of the study had to be abandoned due to difficulties in measurement of true lag. All of the quoted times which follow and all mention made of times refer to the actual amount of labor used on each carcass. Instead of timing each job 10 times and then moring on to another one, a specific animal was chosen and the time for each successive job performed on it was recorded until the carcass was moved into the cooler. Listed below are the five different stages and the individual job elements that are normally performed under each one.

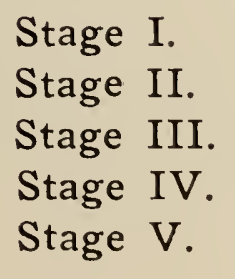

Shackling and sticking.

Scalding and dehairing.

Eviscerating.

Splitting and weighing.

Cleaning offal. 
Stages I through IV constitute the on-line operations. These stages include all the job elements which occur along the killing and dressing line in a sequential order and are performed by workers who typically are in stationary positions performing specific manipulations upon the carcasses as they move by the workers' stations.

Stage $V$ is off-line operations performed on detached parts of the carcasses. In most of the plants the job elements included in this stage are not geared to the rate of flow of carcasses moving along the killing and dressing line.

\section{Stage I-Shackling and Sticking}

This stage includes those job operations which usually begin with the assembling of live hogs in holding pens and ends on the bleeding rail. Normally the following job elements are included:

\section{Driving to holding pens \\ Driving to shackling pens Sticking \\ Shackling}

Occasionally a plant operator will have the live hogs washed during this stage to remove excess mud and dirt. Spraying the hogs is said to cool them and minimize weight loss resulting from frantic milling about in the holding pens.

\section{Stage II-Scalding and Dehairing}

This stage includes those operations which begin when the carcass is dropped into the scalding tank and end with the scraping or washing of a carcass before it is opened. The following jobs elements are accomplished during this stage:

$\begin{array}{ll}\text { Dropping carcasses into the } & \text { Gambreling } \\ \text { scalding tank } & \text { Hoisting to rail } \\ \text { Scalding } & \text { Singeing } \\ \text { Dehairing, either mechanically } & \text { Dropping head } \\ \text { or manually } & \text { Removing feet } \\ \text { Scraping } & \text { Washing }\end{array}$

At some plants the head is not dropped during this stage, but for comparative purposes the labor time required for this operation has been included in this stage. In one plant, a depilator was used in the dehairing process, but to avoid disclosure of the plant, the entire operation has been included under dehairing. Since most plants scald a number of hogs at one time, the labor time of tub operators has been prorated according to the average number of hogs in the tank at one time. 


\section{Stage III-Eviscerating}

This stage includes those operations which usually begin with carcass opening or bung pulling and continue through final trimming, pulling leaf fat, remoring kidneys, and facing hams. A typical succession of job elements would be:

Opening carcass

Splitting aitch bone

Pulling bung

Removing and separating viscera

Removing and separating pluck

Pulling leaf lard
Facing hams

Exposing the femoral artery

Washing carcass

Splitting rib casing

Removing kidneys

\section{Stage IV-Splitting and Weighing}

This stage includes those operations which generally begin with the splitting of the carcass and end when the carcass has been mored into the cooler. Specific jol elements include:

$\begin{array}{ll}\text { Splitting carcass } & \text { Inspecting } \\ \text { Weighing } & \text { Washing } \\ \text { Grading and marking } & \text { Moving to cooler } \\ \text { Spreading } & \end{array}$

Inspection is placed under this stage for this report although in practice it is generally done at an earlier time along the lilling line.

\section{Stage V-Cleaning Offal}

This stage differs from the first four in that these operations do not necessarily occur as the carcass is moved along the killing line. In fact, they most often take place after the killing line is shut down for the day. This stage includes a number of activities that are performed on detached parts of the carcass, either in the killing room or a room nearby. In the larger plants, these operations occur at the same time hogs are moving along the killing line. In smaller plants. these detached parts generally are collected in containers and sidelined until a time when the employees of the killing line can be transferred.

These operations normally include the following:

Removing ears and eyes

Trimming head

Removing jaw or cheek meat

Pulling jaw
Removing tongue

Stripping and cleaning large and small casings

Emptying and weighing stomach 
Splitting head

Removing brains and pituitary gland
Trimming liver and removing gall bladder Removing spleen

This list is not complete, nor do all of these operations occur in a given plant. In some plants, especially those with smallest volume, very few of these operations are performed. These plants elect to sell most of the by-products to other concerns who use the edible portions in consumer products, and turn the inedible portions into tankage, bonemeal, and similar feed or fertilizer products.

\section{LABOR REQUIREMENTS}

The labor required for each of the on-line stages is shown, by plants, in Figure 1, based on the data in Table I of the Appendix. The plants are arrayed from highest to lowest number of hogs killed annually. The total on-line labor per head decreases as the annual volume increases. This relationship is more readily noted by grouping the plants into three size categories and presenting an average for each of the categories, Figure 2. From an average of $71 / 2$ minutes per head for plants killing more than 15,000 head annually, the labor

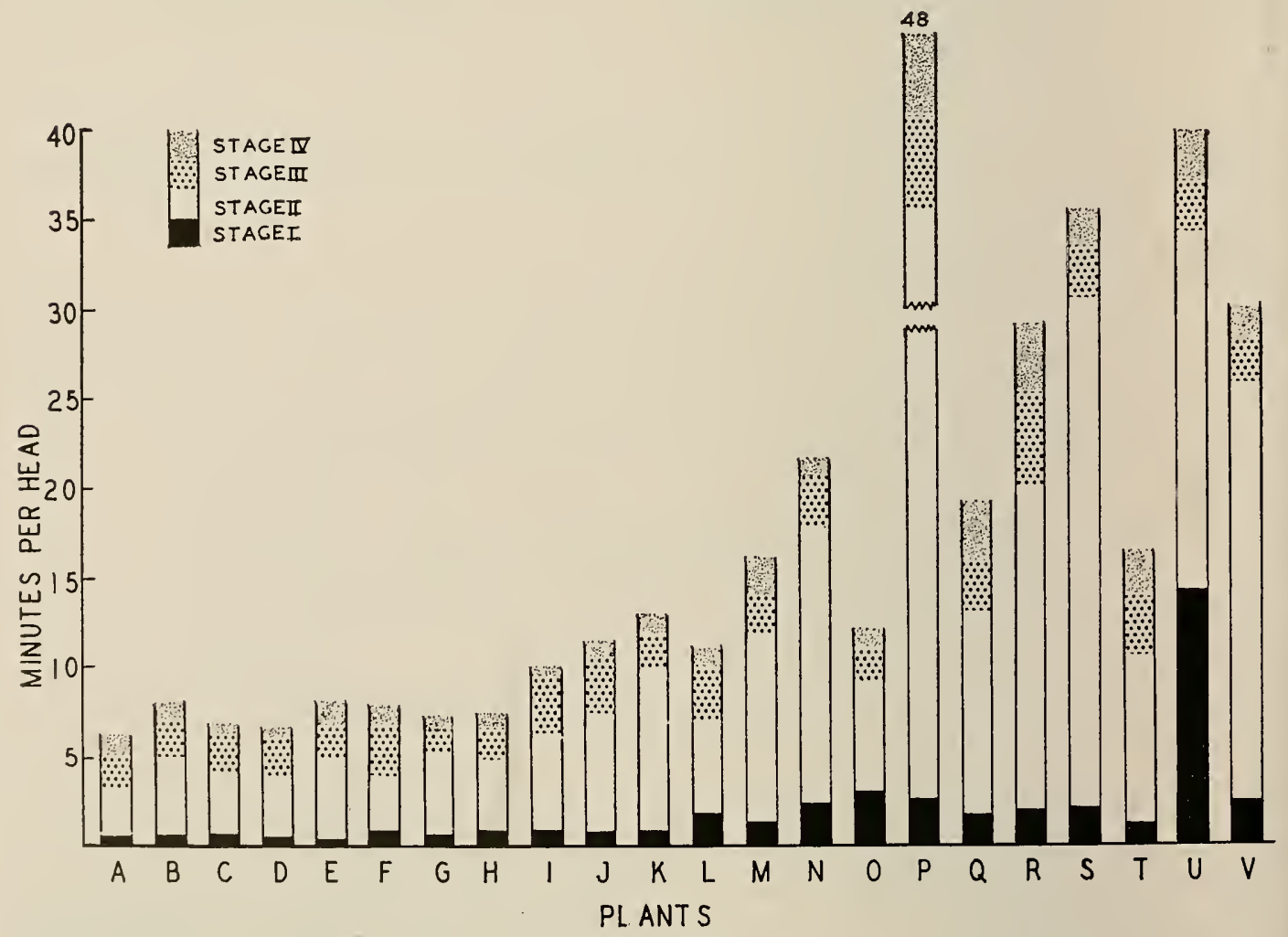

FIGURE 1. Labor utilization in hog slaughtering operations of non-federally inspected plants in Northeastern United States, 1960-61. 
The best job of cleaning hogs was associated with longer scalding tanks and U-Bar dehairers rather than grate-type dehairers.

No one plant among the 22 has the lowest labor input for each of the four stages. Plants D and E are lowest in labor use for Stage I, $A$ and $F$ for Stage II, G and $H$ for Stage III, and C, D and I for Stage IV. Plants D and E are lowest under Stage I because their holding and shackling pens are large and close together. This permits large numbers of hogs to be assembled and transferred between pens each time the operations are performed. Plants $\mathrm{A}$ and $\mathrm{F}$ are low in labor use under Stage II primarily because the efficiency of their dehairing machines cut down on the labor required for scraping. At plants $G$ and $H$ there is very little specialization under Stage III, and one man at each plant does practically all of the eviscerating and trimming. In spite of the absence of specialization, these two plants have the lowest labor inputs for Stage III. Plants C, D, and I use the least amount of labor for Stage IV because of a number of reasons. At plant $D$ the carcass is split rapidly with an ax; this decreases the labor for this stage. At plants $C$ and I several carcasses are weighed at one time and then moved into a cooler that is located very close to the scales.

\section{EFFICIENCY STANDARDS}

On the basis of the time required for Stages I through IV, an hourly flow rate was calculated for each plant. The calculated flow rate is obtained by dividing the average time spent by each worker on a hog into the number of seconds in one hour. For example, assume that the average amount of labor spent on each hog at plant $Z$ is 10 minutes (600 seconds), and there are 10 workers along the killing and dressing line. Under these conditions each laborer would work an average of 60 seconds on each hog. Dividing this average labor time into the number of seconds in one hour (3600) gives a calculated

\section{0}

flow rate of 60 hogs per hour. The next step was to determine the actual flow rate for each plant. The actual flow rate is an average hourly count of the carcasses as they moved into the coolers. A comparison of the actual and the calculated flow rates is shown in Figure 3 and Appendix Table II.

There are several reasons which might account for the difference between the calculated and the actual flow rate. Among these are the time it takes a carcass to move from one station to another (transit time), loss of time due to transfer of laborers from one station to another along the line (labor transfer loss), lag time created by a bottleneck at one station which delays the movement of carcasses 


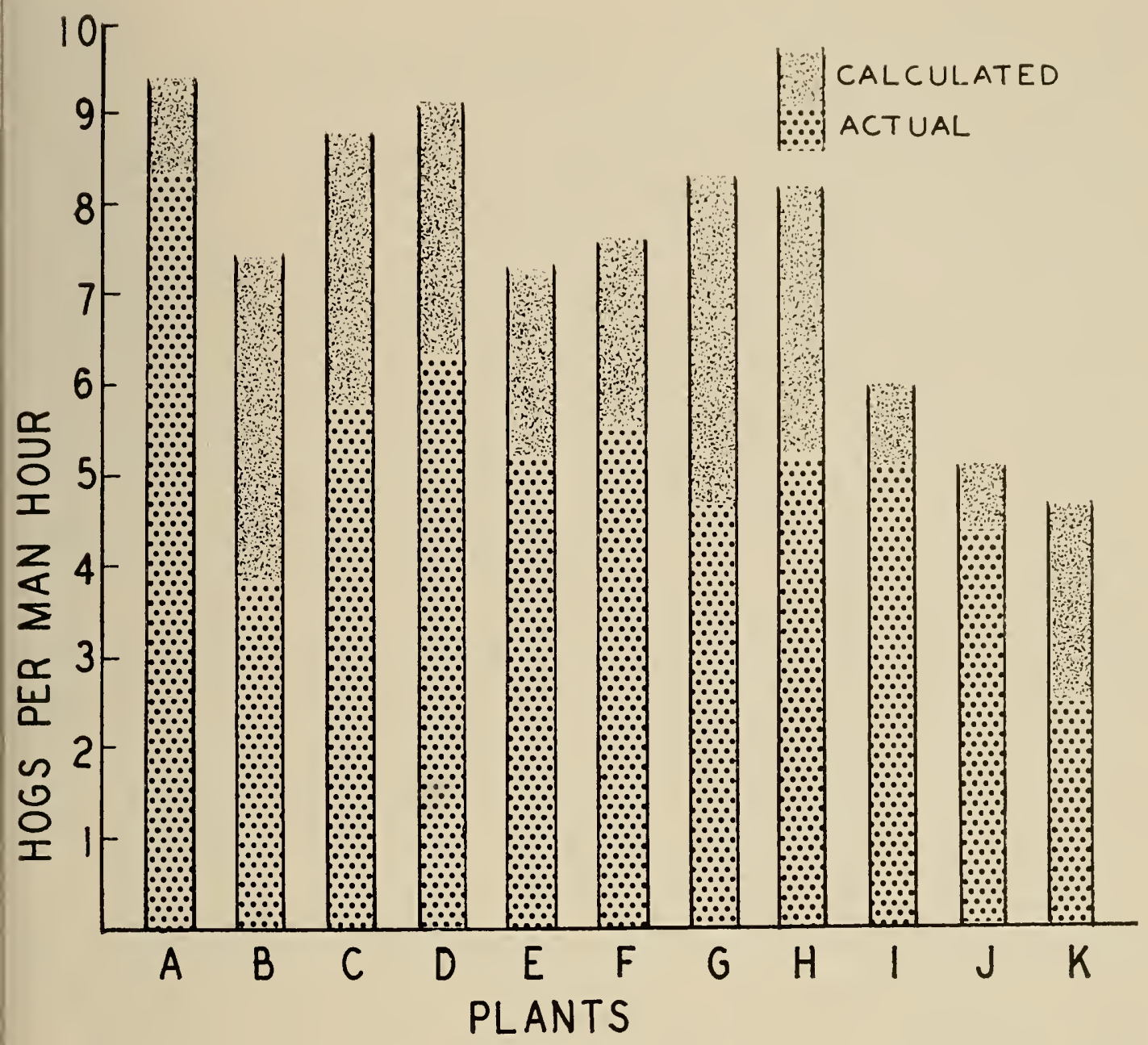

FIGURE 3. A comparison of the calculated and actual flow rate in the hog slaughtering operations.

all along the line, mechanical failures of equipment, and time lost due to human frailties. All of these factors create lag time. Attempts to measure lag time in this study proved fruitless.

In plants $\mathrm{A}$, I and $\mathrm{J}$ the actual flow rate was 85 to 88 per cent of the calculated rate, while at plants $B, G$, and $K$ the actual rate was less than 60 per cent of the calculated rate, Figure 3 . When the actual rate approaches the calculated rate, the laborers are more fully employed. This does not mean that the labor input is being used in the most efficient manner. A plant could have a fully employed labor force, but still have an abnormally low flow rate due to a low level of mechanization or poorly performing machinery and equipment. On the other hand, a plant may have complete utilization of labor and suffer an abnormally low flow rate due to workers spending unreasonable amounts of time to perform certain jobs. Suffice to say that in those plants where the ratio is near 50 per cent, manage- 
ment should be on guard to cut lag time, whether it be due to machinery, personnel, or prior management decisions.

Like most business enterprises, slaughter plant operators need some type of standards by which they can measure the performance of their firms. For plants of the sizes and types included in this study, a pragmatic set of standards derived from the data might prove useful; that is, plant operators could select as a standard the labor inputs of those plants which use the least amount of labor under each of the four stages and measure their own performance against the average of these low plants. In Table 1 figures are shown for those two plants with lowest labor inputs under each stage. A comparison of these data with the labor inputs shown in Figure 1 indicates that most operators could decrease their labor requirement in one or more of the different stages.

Table 1. Synthesized Labor Standards for Slaughtering Hogs in NonFederally Inspected Plants, Northeastern United States, 1960-61

\begin{tabular}{|c|c|c|c|c|}
\hline \multirow[b]{2}{*}{$\begin{array}{l}\text { Plant SIZE } \\
\text { (No. OF HeAd) }\end{array}$} & \multicolumn{4}{|c|}{ Labor Requirement Per Head (Man-Minutes and Seconds) } \\
\hline & $\begin{array}{c}\text { STAGE I } \\
\text { SHACKLING } \\
\text { STICKING }\end{array}$ & $\begin{array}{c}\text { Stage II } \\
\text { SCALDING } \\
\text { DEHAIRING }\end{array}$ & $\begin{array}{c}\text { Stage III } \\
\text { Eviscerating }\end{array}$ & $\begin{array}{l}\text { StaGe IV } \\
\text { SPLITTING } \\
\text { WEIGHING }\end{array}$ \\
\hline $\begin{array}{c}16,000-108,000 \\
4,000-15,000 \\
150-2,000\end{array}$ & $\begin{array}{l}0: 32 \\
0: 52 \\
1: 27\end{array}$ & $\begin{array}{l}2: 45 \\
5: 18 \\
7: 40\end{array}$ & $\begin{array}{l}1: 29 \\
1: 51 \\
2: 10\end{array}$ & $\begin{array}{l}: 31 \\
: 45 \\
: 58\end{array}$ \\
\hline $\begin{array}{c}\text { Total TIME FOR StaGes } \\
\text { I THROUGH IV } \\
\text { (ON-Line) }\end{array}$ & GES & $\begin{array}{c}\text { Stage V } \\
\text { (OFF-LiNe) } \\
\text { Cleaning OfFal }\end{array}$ & \multicolumn{2}{|c|}{ Total All Stages } \\
\hline $\begin{array}{l}5: 17 \\
8: 46\end{array}$ & $*$ & $2: 08$ & & $7: 25$ \\
\hline
\end{tabular}

* Not available.

$\doteqdot$ Fxcluding Stage V.

The most critical factor in reducing labor inputs is the efficiency of the dehairing machine, which in turn depends upon the effectiveness of the scalding equipment. Frequently minor, relatively inexpensive mechanical aids will appreciably affect labor efficiency. For example, some plants wash carcasses by dipping water from a nearby barrel. Others have conveniently located overhead outlets with spring valves that open when squeezed but close automatically when released. Still others have nozzles located on either side of the rail at several pertinent locations that spray water continuously on the carcasses as they move along the line. A plate, slightly longer than the gambrel, attached to a section of the rail steadies the carcass and facilitates the splitting operation. A skilled operator usually can split a carcass more rapidly with an ax than it can be saved. 


\section{Cattle Slaughtering Operations}

Someone once remarked that the necessary equipment to start a cattle slaughtering operation consisted of a knife and rope. Although the statement is basically true, no operations of this size were included in this study. Twenty-seven plants were selected for the study of cattle slaughtering; 12 classified as large and 14 classified as medium non-feclerally inspected slaughter plants. The classification for one plant is unknown as the operator refused to disclose his annual slaughter volume. At all of the establishments except one, other species and classes of livestock were slaughtered in addition to cattle. The one exception slaughtered cattle only.

\section{ORGANIZATION AND PROCEDURE}

A conspicuous and common characteristic among these plants is the low level of mechanization. At most plants, the machinery and equipment for slaughtering and dressing cattle consists of a stunning gun (or sledge hammer), hoists, beef beds, overhead rails, knives, and saws. Technological improvements such as mechanical hide pullers, moving chains, and skinning cradles are noticeably absent.

Associated with the low level of mechanization is a relatively high labor input per slaughtered animal. At the same time, there is very little job specialization. One worker may do 5 or 6 separate jobs on a carcass before it is finally pushed into the cooler.

Normally cattle flow through the killing room in the following sequence. From the holding pens they move into stunning rooms where they are stunned, shackled and hoisted to bleeding rails. Next they are lowered to the floor and positioned on beef beds for the flooring operations. After the flooring operations are completed, the carcass is hoisted, the hide removed and then eviscerated. The carcass is then split and trimmed. After final trimming, the carcasses are washed, weighed, and moved into coolers. High grade carcasses are generally shrouded before being moved into the coolers.

These operations can be and are performed in varied ways among the plants and for that reason several operational stages have been delineated. By grouping certain job elements under each stage, some meaningful comparisons can be made that would not otherwise be possible. These production stages and the job elements normally included under each are listed below.

\section{Stage I. Pre-Slaughter and Slaughtering. \\ Stage II. Flooring. \\ Stage III. Rumping and Backing.}


Stage IV. Eviscerating and Splitting.

Stage V. Final Dressing.

Stage VI. Cleaning Offal.

\section{Stage I-Pre-Slaughtering and Slaughtering}

The first stage includes those operations which usually begin with the driving of cattle to the stunning room and end when the carcass is being positioned for flooring operations. The following job elements normally are included:

Driving to holding pens

Washing the live animal

(occurs infrequently)

Driving to knocking pens

Stunning, knocking, or shooting

Shackling

Hoisting
Cutting throat or sticking Skinning and removing feet (At most plants this is done under Stage II)

Removing tags

Skinning and removing head Removing tongue

\section{Stage II-Flooring}

The second production stage is comprised of those operations which begin with the positioning of the carcass for flooring and most often end with the carcass being positioned for rumping and backing. Job elements included are:

Positioning for flooring

Laying out hide pattern

Skinning and removing feet

Udder removal
Skinning out sides and belly (flooring)

Splitting rib casing and aitch bone

At some plants the carcass is washed during this stage. Whenever this occurs the job element is transferred to Stage IV.

\section{Stage III-Rumping and Backing}

This stage includes all of those operations which begin with the positioning of the carcass for rumping and backing and end normally just prior to the pulling of viscera. Included among these job elements are the following:

Hoisting for rumping and backing

Skinning tail
Removing tail and bung Rumping and backing

\section{Stage IV-Eviscerating and Splitting}

This production phase includes a number of jobs that do not occur in an orderly sequence. That is, they may be done at an earlier 
or later time than that indicated by the title of this stage, but for the purposes of this study, they are transferred to this stage. For instance, carcass washing is not done at the same time and place among the plants, but regardless of where it occurs, all washing is transferred to this stage. Job elements assembled nnder this stage are:

\section{Pulling viscera \\ Separating pluck \\ Splitting carcass}

Splitting neck

Washing carcass

Separating viscera

\section{Stage V-Final Dressing}

Stage $V$ is comprised of final operations on the carcass before it is moved into the cooler. This production phase contains a number of jobs that are unrelated except as they all occur as finishing operations. Specific job elements performed are:

Hoisting carcass to tracks

Breaking feather bones

Final trimming of fat, bone, and meat

Weighing
Branding and spreading Skewering

Shrouding

Moving to cooler

\section{Stage VI-Cleaning Offal}

This stage is comprised of operations which, broadly speaking, are adjunct activities that may or may not occur simultaneously with the movement of the carcass along the killing and dressing line. Further, these jobs may or may not be performed in the killing and dressing rooms. Quite often such detached parts as the head and intestines will be stored in vats in an adjacent room until the killing and dressing line is closed down. The laborers along the line are then transferred there and perform the job elements included under this production phase. These job elements include the following:

Opening paunch

Cleaning paunch

Cleaning and scalding tripe Trimming head
Washing and separating offal Washing and cleaning intestines Weighing hide Inspecting

Admittedly, the above list does not include all of the jobs performed on what is generally described as edible and inedible byproducts. It does, however, indicate the nature and type of jobs included under this production stage. 


\section{LABOR REQUIREMENTS}

The labor nsed at each plant to carry out these different productive stages is presented in Figure $t$ and Appendix Table III. The plants are arrayed from highest to lowest number of head killed annually: Considering on-line labor by itself (Stages I through V), the data collected in this study point out no definite association between labor use and the volume of slaughter. In general, the labor input is highest for those plants whose annual volume is less than 1,000 head. However, as plant size increases from 1,000 to 13,000 head, there is no striking difference in the amount of labor used per head. The total on-line killing and dressing time varies from a low of $231 / 2$ minutes per head to a high of 55 minutes. Excluding these 7 plants where less than 1,000 head are slaughtered and Plant D, which is quite unusual, the on-line labor requirement for most of the remaining plants falls within the range of 30 to 37 minutes per head.

Under each of the on-line stages, there are some plants that use relatively large amounts of labor and some that use relatively small amounts of labor. No one plant among the 27 included in the study has the lowest labor input for each of these five stages. However, the labor used under each stage at Plant $D$ ranks very near the lowest recorded for each stage. At this particular plant their equip-

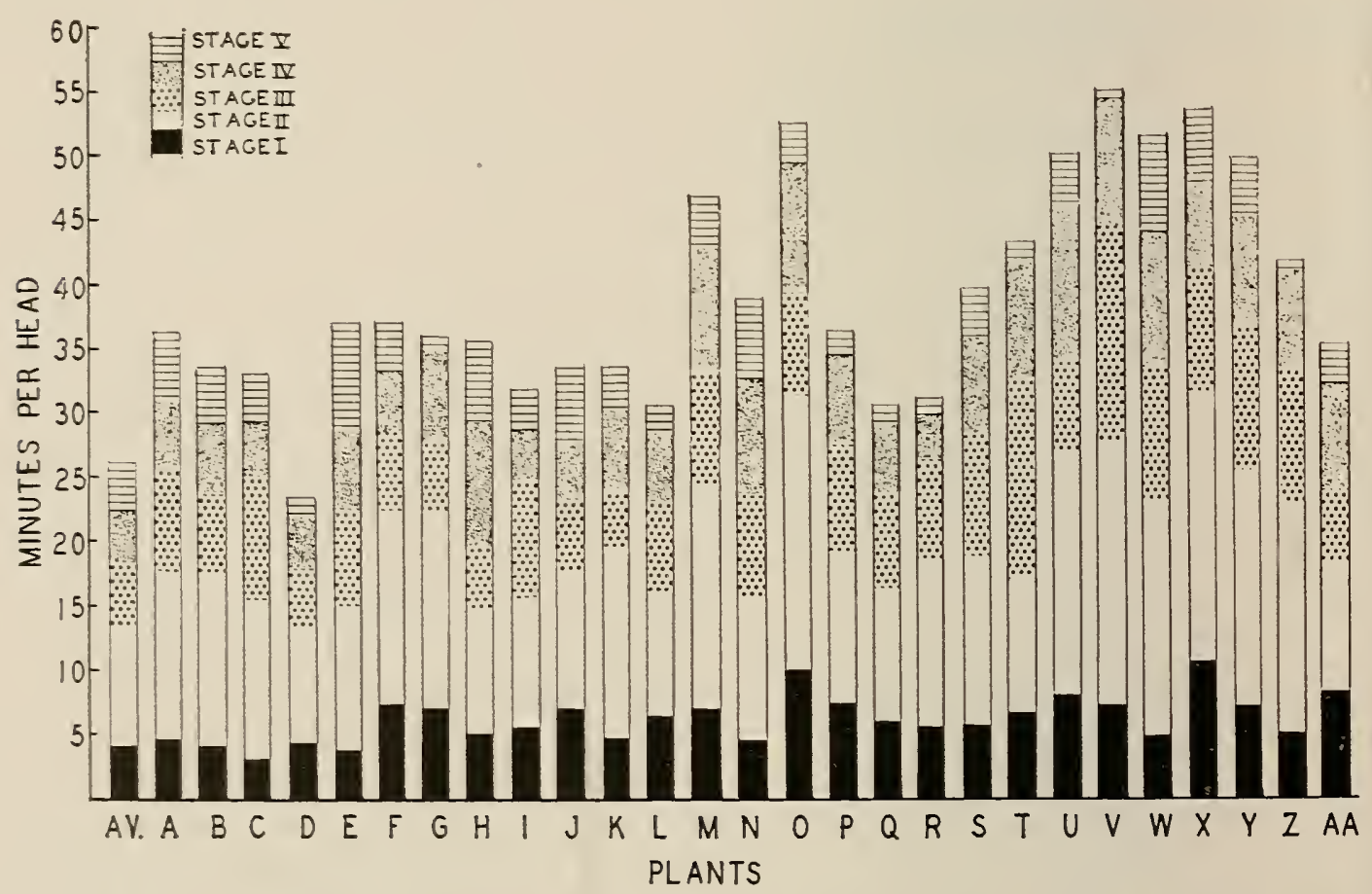

FIGURE 4. Labor utilization in cattle slaughtering operations of non-federally inspected plants in Northeastern United States, 1960-61. 
ment included a homemade skinning cradle, viscera hoist, and a spring-type gambrel hook to hoist cattle to the rail. All of these mechanical aids plus the diligence of the workers led to lower labor requirements. Further, none of the carcasses was shrouded while the timed observations were being taken. Consequently, the labor utilization at this plant could very well serve as a guicleline for most of the plants.

\section{EFFICIENCY STANDARDS}

Somewhat arbitrarily, Table 2 has been synthesized as a practical set of labor standards for plants of the size and type included in this study. Since there is no noticeable difference in the quantity of labor used among plants killing 1,000 or more head, only one set of standards is presented for the plants whose annual volume ranges from 1,000 to 13,000 head. By comparing their individual operations against these standards, plant managers may gain some insights on the efficiency of their labor utilization.

Table 2. Synthesized Labor Standards for Cattle Slaughtering Operations in Non-Federally Inspegted Plants, Northeastern United STATES, 1960-61

\begin{tabular}{|c|c|c|c|c|c|}
\hline \multirow[b]{2}{*}{$\begin{array}{c}\text { Plant SIZE } \\
\text { (No. OF HEAD) }\end{array}$} & \multicolumn{5}{|c|}{ Labor Requirement Per Head (Man-Minutes and Seconds) } \\
\hline & $\begin{array}{c}\text { STAGE I } \\
\text { SLAUGFTER }\end{array}$ & $\begin{array}{l}\text { STAGE II } \\
\text { FLOORING }\end{array}$ & $\begin{array}{l}\text { STAGE III } \\
\text { RUMPING } \\
\text { BACKING }\end{array}$ & \begin{tabular}{|c|} 
STAGE IV \\
EVISCERATING \\
SPLITTING \\
\end{tabular} & $\begin{array}{l}\text { STAGE V } \\
\text { FINAL } \\
\text { DRESSING }\end{array}$ \\
\hline $1,000-13,000$ & $3: 55$ & $9: 43$ & $5: 03$ & $4: 06$ & $\begin{array}{l}3: 30 * \\
1: 06 \div\end{array}$ \\
\hline \multicolumn{2}{|c|}{$\begin{array}{c}\text { IGTAL TIME FOR STAGES } \\
\text { I THROUGH V } \\
\text { (ON-LINE) }\end{array}$} & \multicolumn{2}{|c|}{$\begin{array}{c}\text { STAGE VI } \\
\text { (OFF-LINE) } \\
\text { CLEANING OFFAL } \\
\end{array}$} & \multicolumn{2}{|c|}{ Total Time All Stages } \\
\hline \multicolumn{2}{|l|}{$23: 53 \dagger$} & \multicolumn{2}{|c|}{$5: 06$} & \multicolumn{2}{|c|}{$31.23 *$} \\
\hline
\end{tabular}

*With shrouding.

$\uparrow$ Without shrouding.

The standards in Table 2 were derived by averaging the labor requirements at those five plants using the least amount of labor under each operational stage. Stage $V$ had to be further divided into those plants that shrouded carcasses and those plants that did not shroud. The quotation for Stage VI was obtained and is applicable only for those plants where separate job elements of this productive phase could be timed with a reasonable degree of accuracy. 



\section{APPENDIX}




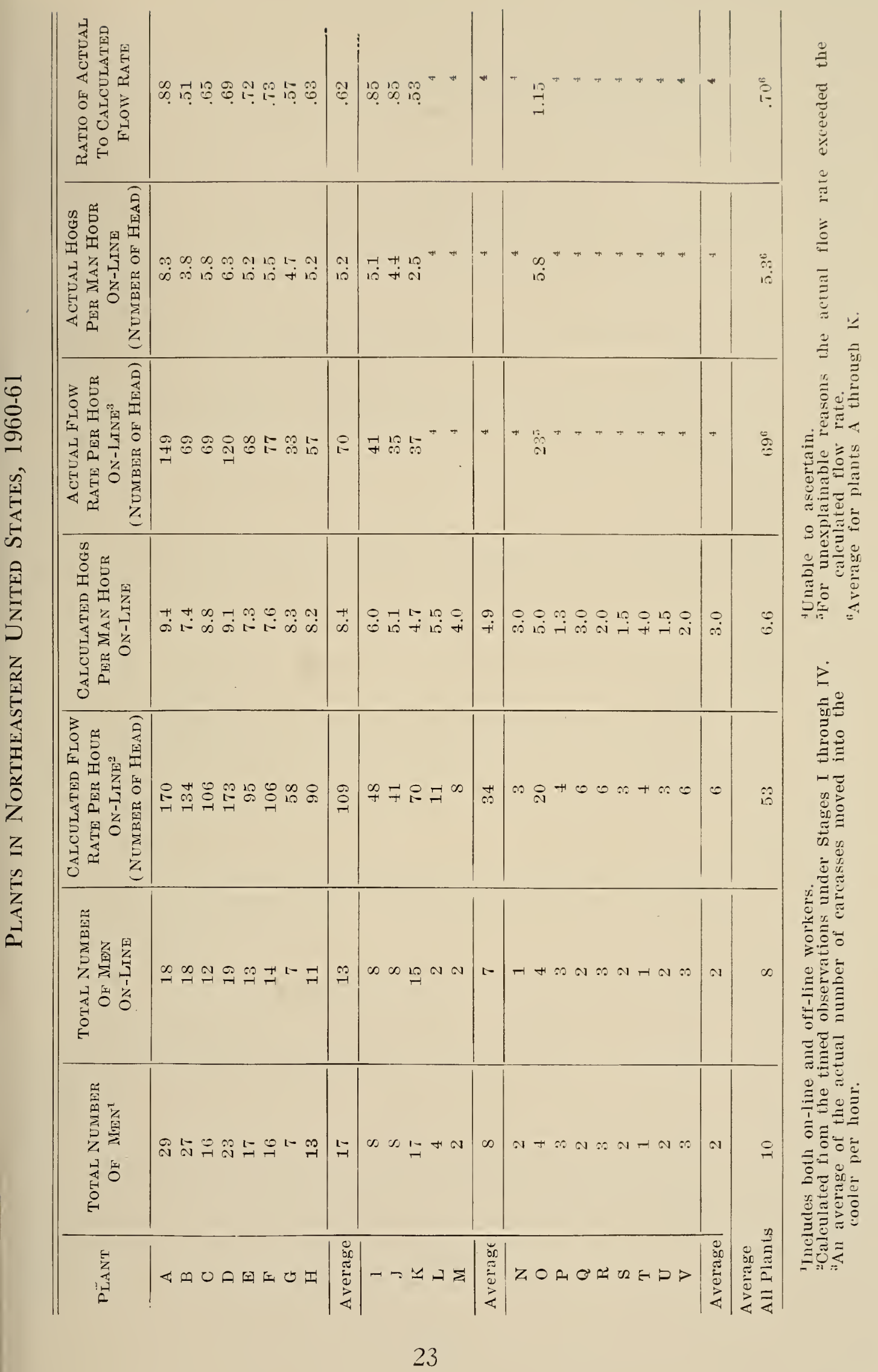




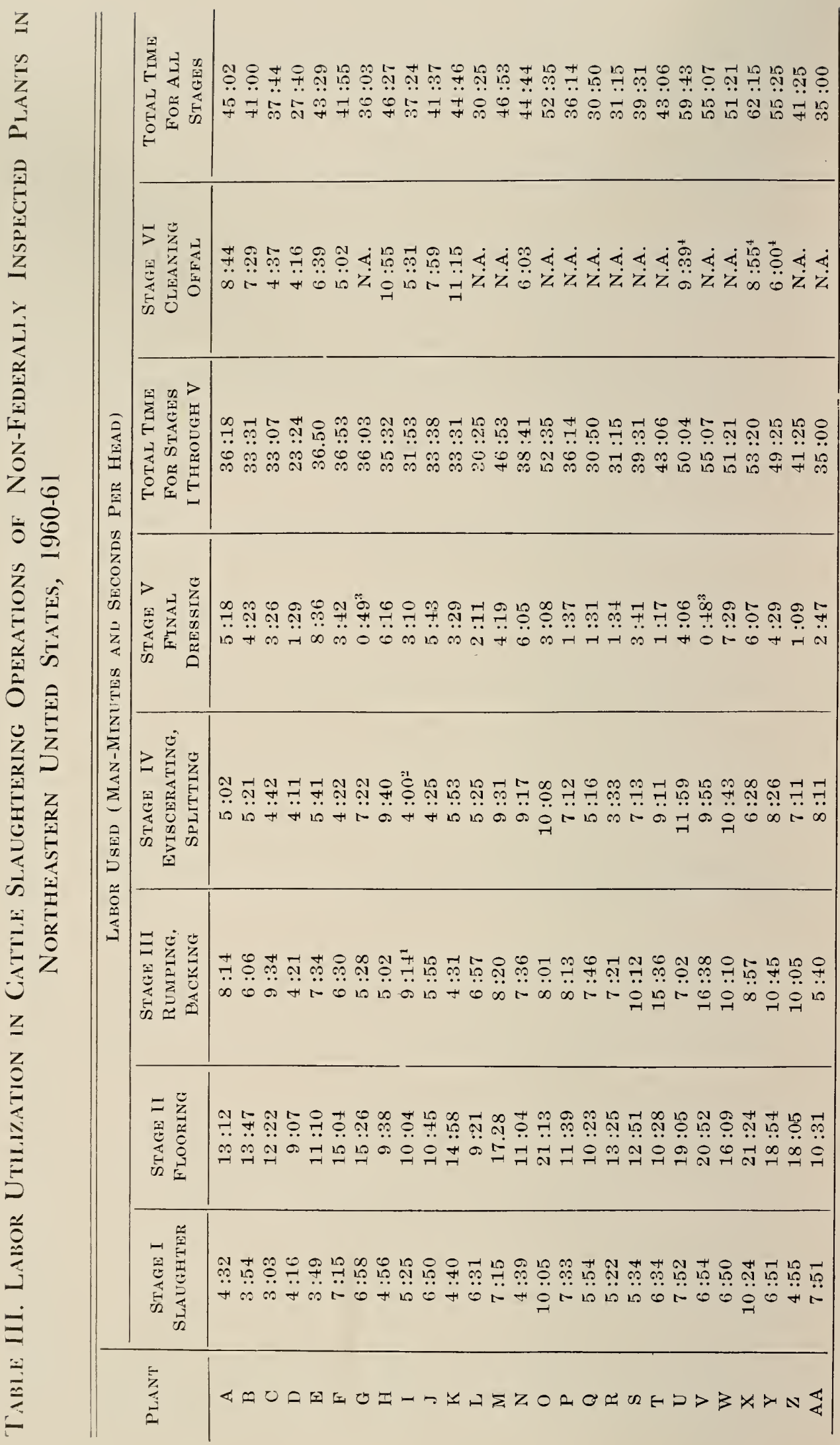

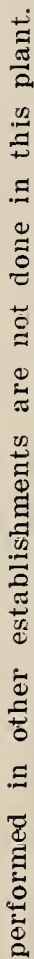

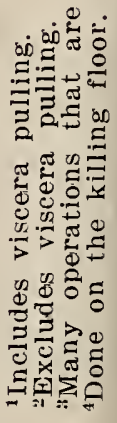




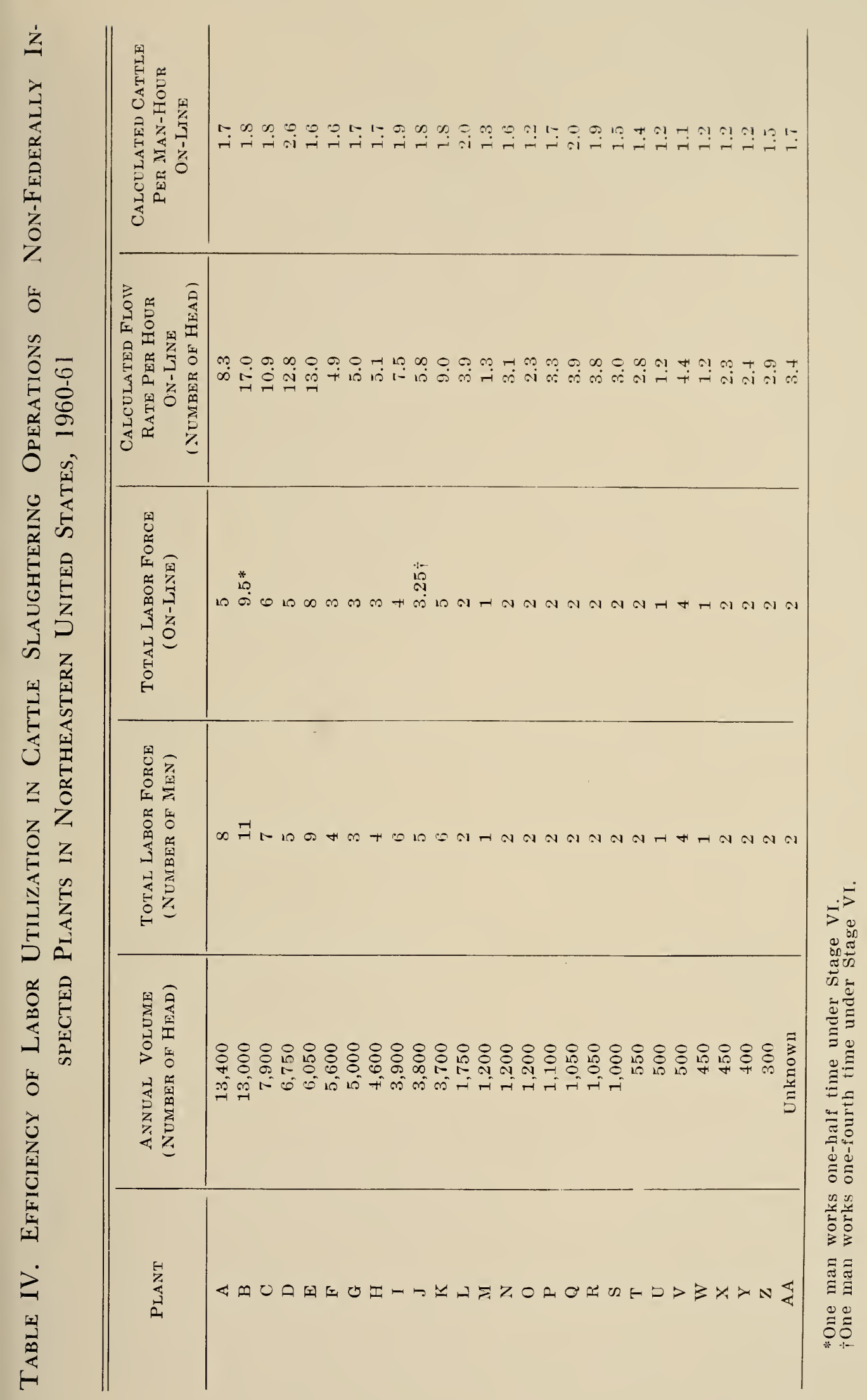






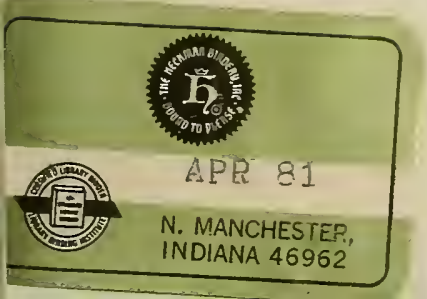


$3, n^{2} \quad 4 \times 49$ 